\title{
СПЕЦИФИКА РИСКОВ ЧАСТНЫХ ПАРТНЕРОВ В УСЛОВИЯХ РЕАЛИЗАЦИИ ПРОЕКТОВ ГОСУДАРСТВЕННО-ЧАСТНОГО ПАРТНЕРСТВА ПРИ ВЫПОЛНЕНИИ ГОСУДАРСТВЕННОГО ОБОРОННОГО ЗАКАЗА *
}

\author{
(c) 2020 Пухова Марина Михайловна \\ кандидат экономических наук, \\ доцент Департамента корпоративных финансов и корпоративного управления \\ Финансовый университет при Правительстве Российской Федерации, Россия, Москва \\ E-mail: MPuhova@fa.ru
}

В статье рассмотрены условия становления и развития системы государственно-частного партнерства в России, определены основные элементы правовой системы функционирования ГЧП как формы экономического взаимодействия. Приведены условия возникновения рисков частных партнеров, исходя из сложившейся ситуации, а также рассмотрены классификации рисков в современной научной литературе. Вместе с тем выявлены специфические условия возникновения рисков ГЧП в сфере гособоронзаказа, а также приведена авторская классификация рисков данной отрасли. Предложены меры по минимизации рисков ГЧП в сфере гособоронзаказа.

Ключевые слова: государственно-частное партнерство, частный партнер, публичный партнер, риски ГЧП, гособоронзаказ (ГОЗ), классификация рисков.

В настоящее время формирование проектов государственно-частного партнерства (ГЧП) в отечественной экономике является достаточно распространенной практикой, в том числе при реализации инфраструктурных проектов. Одной из важнейших составляющих функционирования системы ГЧП в условиях рыночной экономики является ее эффективность. При этом существует несколько способов ее обеспечения, одним из которых является обеспечение повышения эффективности за счет снижения или минимизации рисков. Также в процессе реализации проектов ГЧП у большинства частных партнеров формируются специфические риски, исходя из отраслевого подхода, которые:

- модифицируются относительно сектора экономики, в котором реализуется проект ГЧП;

- имеют базовые условия, связанные со спецификой правовых норм и форм финансирования.

Как следствие вышесказанного, возрастает необходимость формирования признаков специфичности рисков в системе гособоронзаказа (ГО3) для достижения стратегических целей реализации ГЧП и минимизации опасностей и угроз, исходящих, как из внешней, так и из внутренней среды.
Развитие ГЧП берет свое начало в Великобритании, впервые представленное в виде частной финансовой инициативы (PFI). Данный подход был весьма неоднозначно принят правительством страны, однако закрепился в системе реализации социально-ориентированных и производственных проектов как наиболее эффективный инструмент привлечения частных инвестиций и ресурсов.

Стоит отметить, что становление ГЧП в России можно связать с появлением первых законодательных основ в целях привлечения частного капитала и инвестиций в экономику, а также развития эффективных механизмов управления государственным и муниципальным имуществом. Нормативно-правовая база была заложена в Федеральном законе от 21.07.2005 N 115-Ф3 «О концессионных соглашениях» и Федеральном законе от 13.07.2015 N $224-Ф 3$ «О государственно-частном партнерстве, муниципально-частном партнерстве в Российской Федерации и внесении изменений в отдельные законодательные акты Российской Федерации» (224-Ф3). Указанные законодательные акты направлены, прежде всего, на формирование и создание правовых условий повышения инвестиционной привлекательности в россий-

\footnotetext{
Статья подготовлена по результатам научно-исследовательской работы, выполняемой в рамках государственного задания в ФГОБУ ВО «Финансовый университет при Правительстве Российской Федерации» в 2020 году.
} 
ской экономике механизма ГЧП. Приведем анализ основных функций элементов системы ГЧП согласно 224-Ф3 (таблица 1).

Следует отметить, что условия для формирования ГЧП (МЧП) в России с введением 224-ФЗ стали более прозрачны, справедливы и юридически обоснованы, что также позитивно сказывается на развитии данного вида экономического взаимодействия в нашей стране. Однако следует учитывать, что правовое закрепление ответственности и обязательств, подразумевает и справедливое распределение рыночных и иных рисков. Важно отметить, что риски частного партнера носят характер общеэкономических и специфических, которые связаны с реализацией соглашения ГЧП. Вместе с тем, специфичность рисков также будет связана со сферой деятельности, а именно со сферой ГОЗ. Исходя из этого, следует более детально рассмотреть условия формирования ГЧП, согласно законодательству.
Согласно Федеральному закону от 29.12.2012 N 275-Ф3 «О государственном оборонном заказе» (275-Ф3), такая форма взаимодействия как ГЧП не предусмотрена в прямом своем проявлении, а именно реализация ГОЗ подразумевает контрактную систему распределения бюджетных средств. Однако, согласно данному 275-ФЗ, головной исполнитель в праве формировать кооперацию и привлекать соисполнителей контракта через собственные контракты. Вместе с тем, в законе нет определенных требований к форме контрактных и договорных отношений между головным исполнителем и другими исполнителями в рамках их кооперации, а значит, форма ГЧП при реализации ГОЗ применима в контексте соисполнения государственного контракта.

Несмотря на закрепление большей части ответственности при реализации ГОЗ за головным исполнителем, часть рисков может быть передана частному партнеру при заключении соглаше-

Таблица 1. Функции элементов системы ГЧП согласно 224-Ф3

\begin{tabular}{|c|c|c|}
\hline $\begin{array}{c}\text { Элемент ГЧП } \\
\text { (МЧП) }\end{array}$ & Отражение в 224-Ф3 & Основные функции \\
\hline ГЧП (МЧП) & $\begin{array}{l}\text { Юридически оформленное партнерство } \\
\text { между представителем государства (муни- } \\
\text { ципалитета) и частного бизнеса, которое } \\
\text { направлено на привлечение в экономику } \\
\text { частных инвестиций, обеспечение по- } \\
\text { вышения качества товаров, работ и услуг } \\
\text { государственных органов власти. }\end{array}$ & $\begin{array}{l}\text { Данный элемент дает свободу органам } \\
\text { государственной власти в заключении } \\
\text { соглашений с частными инвесторами, дер- } \\
\text { жателями капитала, в целях распределения } \\
\text { рыночных рисков при реализации своей } \\
\text { деятельности по предоставлению работ, } \\
\text { услуг и производству товаров, а также для } \\
\text { повышения их качества и конкурентоспо- } \\
\text { собности. }\end{array}$ \\
\hline $\begin{array}{c}\text { Соглашение о ГЧП } \\
\text { (МЧП) }\end{array}$ & $\begin{array}{l}\text { Является договором гражданско-правового } \\
\text { характера между представителем государ- } \\
\text { ства (муниципалитета) и частного бизнеса, } \\
\text { заключаемый на срок не менее 3-х лет. }\end{array}$ & $\begin{array}{l}\text { Данный элемент закрепляет форму, поря- } \\
\text { док и условия договорных отношений при } \\
\text { ГЧП (МЧП), снимая правовые риски с обоих } \\
\text { сторон-участниц. }\end{array}$ \\
\hline $\begin{array}{c}\text { Публичный } \\
\text { партнер }\end{array}$ & $\begin{array}{l}\text { Органы государственной власти, представ- } \\
\text { ляющие Российскую Федерацию, субъект } \\
\text { или муниципальное образование в согла- } \\
\text { шении о ГЧП (МЧП). }\end{array}$ & $\begin{array}{l}\text { Позволяет сформировать условия для при- } \\
\text { влечения частных инвестиций и ресурсов, } \\
\text { а также определяет ответственное лицо и } \\
\text { границы его ответственности. }\end{array}$ \\
\hline Частный партнер & $\begin{array}{l}\text { Юридическое лицо, зарегистрированное } \\
\text { в России, которое становится стороной } \\
\text { соглашения ГЧП (МЧП). }\end{array}$ & $\begin{array}{l}\text { Формирует условия для определения } \\
\text { границ прав и свобод частного партнера, } \\
\text { а также определяет его ответственность и } \\
\text { порядок реализации деятельности в рам- } \\
\text { ках соглашения о ГЧП. }\end{array}$ \\
\hline $\begin{array}{c}\text { Принципы ГЧП } \\
\text { (МЧП) }\end{array}$ & $\begin{array}{l}\text { ГЧП (МЧП) имеет ряд принципов, позволя- } \\
\text { ющих эффективно использовать данный } \\
\text { способ экономического взаимодействия. }\end{array}$ & $\begin{array}{l}\text { Принципы, приведенные в 224-Ф3, опреде- } \\
\text { ляют несколько важных условий эффектив- } \\
\text { ного взаимодействия между публичным и } \\
\text { частным партнерами, а именно транспа- } \\
\text { рентность действующего соглашения, } \\
\text { обеспечение справедливой конкуренции, } \\
\text { равенство и отсутствие правовой дис- } \\
\text { криминации сторон, добросовестность } \\
\text { исполнения обязательств и справедливое } \\
\text { распределение рисков. }\end{array}$ \\
\hline
\end{tabular}

Источник: составлено автором 
ния ГЧП, а вместе с ними и специфичность, связанная с данной сферой.

Так, к основным специфичным условиям ГОЗ следует отнести:

- соблюдение режима использования отдельного счета для реализации проекта (контракта);

- необходимость соблюдения жестких условий конфиденциальности или режима секретности;

- специфика формирования ценовой политики;

- высокая операционная нагрузка в связи с более высоким требованиями мониторинга и контроля за исполнением ГОЗ.

Данные условия формируют специфические риски частных партнеров при реализации ГОЗ в рамках ГЧП с головными исполнителями.

Теоретическая основа определения и классификации рисков ГЧП берет свое начало в классической теории рисков, в связи с чем, многие исследователи определяют основные группы рисков в соответствии с ней, а именно как: финансовые риски; экономические риски; политические риски; правовые риски; операционные риски и т.п. Примером классической систематизации рисков ГЧП может служить классификация М.Ю.Соколова [1], который определяет риски в соответствии с факторами или этапами их возникновения. Более широкий перечень рисков ГЧП представляет классификация, предложенная О.А.Рябущенко, в основе которой лежат три признака: сфера возникновения; причины возникновения; покупательная способность денег [2]. Четыре группы рисков ГЧП выделяет В.Г.Варнавский [3]. В сравнении данные классификации приведены в таблице 2.

Вместе с тем, приведенные классификации рисков не учитывают специфики ГОЗ, условия которого могут отражать отдельные специфические риски. Такую классификацию можно сформировать на основе специфичных условий ГОЗ (таблица 3).

Представленная классификация отобража-

Таблица 2. Классификации рисков ГЧП

\begin{tabular}{|c|c|c|}
\hline $\begin{array}{c}\text { Автор } \\
\text { классификации }\end{array}$ & $\begin{array}{c}\text { Методология } \\
\text { классификации }\end{array}$ & Признаки классификации (риски) \\
\hline Соколов М.Ю. & $\begin{array}{l}\text { Классификация по фак- } \\
\text { торам и этапам возник- } \\
\text { новения }\end{array}$ & $\begin{array}{l}\text { 1) По этапам: ретроспективные, текущие, перспективные. } \\
\text { 2) По факторам: политические, правовые, экономические, } \\
\text { внешние, внутренние, чистые, динамические, производ- } \\
\text { ственные, общественные, коммерческие, финансовые, } \\
\text { валютные, инвестиционные. }\end{array}$ \\
\hline Рябущенко О.А. & $\begin{array}{l}\text { Классификация по сфере } \\
\text { возникновения, при- } \\
\text { чинам возникновения, } \\
\text { исходя из покупательной } \\
\text { способности денег }\end{array}$ & $\begin{array}{l}\text { 1) По сфере возникновения: производственные и финан- } \\
\text { совые. } \\
\text { 2) По причинам возникновения: естественные и полити- } \\
\text { ческие. } \\
\text { 3) Исходя из покупательной способности денег: инфляци- } \\
\text { онные, валютные и дефляционные. }\end{array}$ \\
\hline Варнавский В.Г. & $\begin{array}{l}\text { Классификация по ка- } \\
\text { тегориям общественно- } \\
\text { экономического проис- } \\
\text { хождения }\end{array}$ & $\begin{array}{l}\text { 1) Политические и правовые. } \\
\text { 2) Технические. } \\
\text { 3) Коммерческие. } \\
\text { 4) Экономические, финансовые, валютные. }\end{array}$ \\
\hline
\end{tabular}

Источник: составлено автором

Таблица 3. Классификация рисков частного партнера в условиях выполнения ГОЗ

\begin{tabular}{|c|l|l|}
\hline № п.п & \multicolumn{1}{|c|}{ Специфичные условия } & \multicolumn{1}{|c|}{ Риски } \\
\hline 1. & $\begin{array}{l}\text { Соблюдение режима использования отдельного } \\
\text { счета для реализации проекта (контракта) }\end{array}$ & $\begin{array}{l}\text { Риск неисполнения условий раздельного учета. } \\
\text { Риск операционных задержек при использовании } \\
\text { режима отдельного счета. }\end{array}$ \\
\hline 2. & $\begin{array}{l}\text { Необходимость соблюдения жестких условий } \\
\text { конфиденциальности или режима секретности }\end{array}$ & $\begin{array}{l}\text { Риск утечки конфиденциальной (секретной) ин- } \\
\text { формации об объекте гособоронзаказа. }\end{array}$ \\
\hline 3. & Особенности формирования ценовой политики & $\begin{array}{l}\text { Риск недофинансирования проекта. Риск необо- } \\
\text { снованности цены проекта. Риск срыва сроков } \\
\text { ГОЗ. }\end{array}$ \\
\hline
\end{tabular}


ет возможные отдельные специфические риски частного партнера при реализации ГОЗ, а также условия их возникновения.

В качестве обоснования приведенных специфических рисков можно привести пример АО «Машиностроительный завод «Арсенал». Данное предприятие специализировалось на производстве корабельных пушек и спутников-шпионов, являющихся изделиями государственной важности. В 2016 году в рамках реализации ГОЗ реализовались риски, приведенные в указанной классификации, среди которых были срыв сроков ГОЗ и недофинансирование проектов [4].

Согласно Рекомендациям по реализации ГЧП, утвержденным Министерством экономического развития РФ в 2018 г., риски, приведенные в данной классификации [5], также можно отнести к рискам частного партнера согласно ведомственным рекомендациям (таблица 4).

Реализация проектов ГЧП в условиях выполнения ГОЗ требует от частных партнеров максимальной активизации всех своих ресур-

Таблица 4. Соотношение рисков с «типичной матрицей рисков» по проекту ГЧП

\begin{tabular}{|c|c|c|c|}
\hline Риски & $\begin{array}{c}\text { Риски в соответствии с } \\
\text { типичной матрицей }\end{array}$ & \begin{tabular}{|c|} 
Лицо, которое, как прави- \\
ло, несет ответственность \\
по такому риску согласно \\
типичной матрице
\end{tabular} & $\begin{array}{c}\text { Возможные (экономиче- } \\
\text { ские) последствия }\end{array}$ \\
\hline $\begin{array}{l}\text { Риск неисполнения усло- } \\
\text { вий раздельного учета }\end{array}$ & $\begin{array}{l}\text { Согласование и заключе-- } \\
\text { ние проектных догово- } \\
\text { ров и связанной с ними } \\
\text { документации }\end{array}$ & Частный партнер & $\begin{array}{l}\text { Неверное формирование } \\
\text { себестоимости научно- } \\
\text { технической продукции; } \\
\text { завышение суммы } \\
\text { накладных расходов в } \\
\text { себестоимости научно- } \\
\text { технической продукции, } \\
\text { недостижение закрытия } \\
\text { финансового этапа или } \\
\text { цикла в целом и/или не- } \\
\text { достижение выполнения } \\
\text { иных условий соглашения } \\
\text { ГЧП и пр. }\end{array}$ \\
\hline $\begin{array}{l}\text { Риск операционных } \\
\text { задержек при использо- } \\
\text { вании режима отдельного } \\
\text { счета }\end{array}$ & $\begin{array}{l}\text { Получение разрешений и } \\
\text { согласий от государствен- } \\
\text { ных органов }\end{array}$ & Частный партнер & $\begin{array}{l}\text { Пролонгация сроков } \\
\text { выполнения проекта / } \\
\text { отсутствие возможности } \\
\text { реализации проекта }\end{array}$ \\
\hline $\begin{array}{l}\text { Риск утечки конфиден- } \\
\text { циальной (секретной) } \\
\text { информации об объекте } \\
\text { гособоронзаказа }\end{array}$ & $\begin{array}{l}\text { Соблюдение требований } \\
\text { законодательства }\end{array}$ & Частный партнер & $\begin{array}{l}\text { Задержка выполнения ра- } \\
\text { бот; штрафные санкции } \\
\text { за потерю конфиденци- } \\
\text { альных сведений }\end{array}$ \\
\hline $\begin{array}{l}\text { Риск недофинансирова- } \\
\text { ния проекта }\end{array}$ & $\begin{array}{l}\text { Сроки и стоимость работ } \\
\text { по предварительной раз- } \\
\text { работке }\end{array}$ & Частный партнер & $\begin{array}{l}\text { Задержка выполнения ра- } \\
\text { бот / появление непред- } \\
\text { усмотренных расходов / } \\
\text { недостижение закрытия } \\
\text { финансового этапа или } \\
\text { цикла в целом }\end{array}$ \\
\hline $\begin{array}{l}\text { Риск, связанный с несо- } \\
\text { блюдением норм Поста- } \\
\text { новления Правительства } \\
\text { РФ от 02.12.2017 № } 1465 \\
\text { «О государственном } \\
\text { регулировании цен на } \\
\text { продукцию, поставляе- } \\
\text { мую по государственному } \\
\text { оборонному заказу, а так- } \\
\text { же о внесении изменений } \\
\text { и признании утративши- } \\
\text { ми силу некоторых актов } \\
\text { Правительства Россий- } \\
\text { ской Федерации» }\end{array}$ & $\begin{array}{l}\text { Недостаточный доход / } \\
\text { недостаточные нормы } \\
\text { прибыли }\end{array}$ & $\begin{array}{l}\text { Либо частный партнер, } \\
\text { либо публичный партнер } \\
\text { [в основном, частный } \\
\text { партнер] }\end{array}$ & $\begin{array}{l}\text { Возможность необосно- } \\
\text { ванного завышения цены } \\
\text { на продукцию по ГОЗ; } \\
\text { нарушение порядка } \\
\text { определения начальной } \\
\text { (максимальной) цены } \\
\text { контракта; } \\
\text { Вероятность ошибок при } \\
\text { расчете и обосновании } \\
\text { размера прибыли в соста- } \\
\text { ве цены единицы про- } \\
\text { дукции. Экономические } \\
\text { последствия - штрафные } \\
\text { санкции, недополучение } \\
\text { прибыли. }\end{array}$ \\
\hline
\end{tabular}

Источник: составлено автором на основе Рекомендаций по реализации проектов государственно-частного партнерства // Министерство экономического развития Российской Федерации. 2018 г. URL: https://economy.gov.ru/material/file/cd482f73c0 3b658fa97a2d844c7e39d9/metodic2018.pdf. (дата обращения: 25.04.2020) 
сов, не ограничиваясь только финансированием и управлением проекта. Однако выявленные специфические риски частного партнера могут быть минимизированы за счет мероприятий, предусмотренных в типичной матрице рисков по проектам ГЧП, а исходя из приведенного в таблице 4 соответствия специфических рисков с рисками в типичной матрице, можно предложить следующее:

- Риск неисполнения условий раздельного учета позволит минимизировать: четкое соблюдение законодательства, хорошо организованный и продуманный алгоритм реализации проекта в рамках получаемых средств; реалистичное определение сроков завершения работ по каждому этапу и планирование; четкое определение ответственности частного партнера.

- Риск операционных задержек при использовании режима отдельного счета может быть минимизирован путем методичной организации операционного процесса; определения алгоритма финансирования в рамках выполнения ГО3; выбора ведущих бухгалтерских практик соблюдения раздельного учета.

- Для минимизации риска утечки конфиденциальной (секретной) информации об объекте ГОЗ необходимо осуществление проверок со стороны публичного партнера, получение необходимых юридических консультаций, осуществление мониторинга жизнеспособности системы конфиденциальности и комплаенсконтроля в целом.

- Риск недофинансирования проекта могут минимизировать следующие мероприятия: формирование алгоритма финансирования с соблюдением законодательных норм, адекватные оценки рыночных условий, необходимый задел для внесения корректировок в финансовый план в ходе реализации проекта.

- Минимизация риска, связанного с несоблюдением норм Постановления Правительства РФ от 02.12.2017 N 1465 «О государственном регулировании цен на продукцию, поставляемую по государственному оборонному заказу, а также о внесении изменений и признании утратившими силу некоторых актов Правительства Российской Федерации» осуществляется с помощью разработки внутренних нормативных документов, регулирующих вопросы ценообразования, нормирования затрат, регулярного повышения квалификации работников, отвечающих за финансовые и экономические вопросы.

В заключении необходимо отметить, что при формировании проектов ГЧП в условиях выполнения ГОЗ требуется предварительная проработка как алгоритма финансирования, так матрицы рисков. Данные мероприятия позволят объективно оценить риски при реализации соглашений ГЧП и их минимизировать.

\section{Библиографический список}

1. Соколов М.Ю., Маслова С.В. Государственно-частное партнерство: теоретические основы и практика применения в России и зарубежных странах: учебник. М.: Магистраль, 2017. 268 с.

2. Рябущенко О.А. Оценка эффективности государственно-частного партнерства для развития транспортной инфраструктуры Сибири: автореф. дис. ... канд. экон. наук. Новосибирск, 2011. С. 78-96.

3. Варнавский В.Г., Зельднер А.Г. [и др.]. Основы государственно-частного партнерства (теория, методология, практика): учебник. М.: Анкил, 2015. 315 с.

4. Годовая отчетность АО «Машиностроительный завод «Арсенал» // Арсенал. URL: http://www.mzarsenal.spb. ru/about/information-disclosure/ (дата обращения: 25.04.2020).

5. Рекомендации по реализации проектов государственно-частного партнерства // Министерство экономического развития Российской Федерации. 2018 г. URL: https:/economy.gov.ru/material/file/cd482f73c03b658f a97a2d844c7e39d9/metodic2018.pdf. (дата обращения: 25.04.2020). 